\title{
Globe
}

Revue internationale d'études québécoises

Lori Saint-Martin : Le Nom de la mère. Mères, filles et écriture dans la littérature québécoise au féminin, Québec, Éditions Nota Bene, « Essais critiques », 1999, 331 p.

\section{Élisabeth Rousseau}

Volume 3, numéro 2, 2000

URI : https://id.erudit.org/iderudit/1000590ar

DOI : https://doi.org/10.7202/1000590ar

Aller au sommaire du numéro

Éditeur(s)

Globe, Revue internationale d'études québécoises

ISSN

1481-5869 (imprimé)

1923-8231 (numérique)

Découvrir la revue

Citer ce compte rendu

Rousseau, É. (2000). Compte rendu de [Lori Saint-Martin : Le Nom de la mère. Mères, filles et écriture dans la littérature québécoise au féminin, Québec, Éditions Nota Bene, « Essais critiques », 1999, 331 p.] Globe, 3(2), 192-194. https://doi.org/10.7202/1000590ar d'utilisation que vous pouvez consulter en ligne.

https://apropos.erudit.org/fr/usagers/politique-dutilisation/ 
musique, dans les romans analysés, sont interprétés sur le plan collectif comme "une réponse à la soif du sacré ". "L'écriture salvatrice " est ainsi comparée au "sacre de l'écrivain " de Paul Bénichou.

$$
\begin{array}{r}
\text { Jaap Lintvelt } \\
\text { Université de Groningue (Pays-Bas) }
\end{array}
$$

\section{Lori Saint-Martin}

Le Nom de la mère. Mères, filles et écriture dans la littérature québécoise au féminin

Québec, Éditions Nota Bene, « Essais critiques ", 1999, 331 p.

Le titre de la toute dernière étude de Lori Saint-Martin évoque d'emblée, tout en le déplaçant du père vers la mère, l'un des concepts vedette de la théorie lacanienne, ce fameux nom du père qui place le langage et le symbolique du côté du masculin. C'est dire si SaintMartin ne cherche pas à éviter la polémique, bien au contraire. En effet, dès la quatrième de couverture et tout au long du premier chapitre, essentiellement théorique, l'étude prend fortement position pour l'écriture féminine et entend explorer la relation mère-fille dans l'œuvre d'écrivaines québécoises. Ainsi, à partir des acquis de la psychanalyse et des recherches féministes les plus classiques comme les plus récentes, en sociologie, en histoire culturelle, en anthropologie et autres domaines, l'auteure entreprend de fouiller un vaste corpus sur le thème de la maternité et de la création. Les œuvres étudiées vont, pour le roman, de Gabrielle Roy à Élise Turcotte, en passant par des œuvres aussi variées que celles de Louky Bersianik, Anne Hébert et Nicole Houde qui réécrit le roman de la terre au féminin. L'étude se penche aussi sur la poésie et le théâtre, allant du côté de textes moins canoniques, dont ceux du collectif réuni autour de Pol Pelletier et Louise Laprade. L'une des grandes qualités de l'essai de Lori Saint-Martin est en effet le large échantillon de textes choisis : 52 textes couvrant la majeure partie du XXe siècle. 


\section{RECENSIONS}

La méthode empruntée par l'auteure allie la synthèse théorique, riche et claire, à l'étude fine et attentive des textes. Son analyse s'avère courageuse, efficace et très convaincante. À l'occasion, elle n'hésite pas à remettre les pendules à l'heure et à bouleverser les idées reçues touchant la réception d'un texte; l'on pense, par exemple, à sa charge contre les critiques des années 60 et 70 qui refusaient de voir le caractère intime et familial de la tragédie du Torrent, préférant y lire une métaphore de la Grande Noirceur. Par ailleurs, le découpage retenu par l'auteure permet de faire dialoguer des textes éloignés par les années, les faisant s'éclairer les uns les autres. Fonctionnant par thèmes rattachés à l'idée centrale de la maternité et de la filiation, que ces dernières soit subies, rejetées avec violence, acceptées ou alors transformées, l'essai nous fait traverser tour à tour les "matricides et infanticides ", la " généalogie au féminin ", les rapports entre maternité et création, le travail sur la langue, pour se rendre jusqu'à l'œuvre d'Élise Turcotte qui contient en germe, selon Lori Saint-Martin, les éléments d'un rapport mère-fille réinventé où les deux êtres sont « co-créatrices et collaboratrices".

L'étude de Lori Saint-Martin s'avère donc féconde, assez novatrice et de grande envergure, autant pour le versant théorique que pour les analyses au plus près des textes. Cela dit, et c'est là une réserve importante puisqu'elle se trouve au cœur même du travail de l'auteure, les a priori théoriques liés à l'écriture féminine restent de manière générale peu étayés, un peu contradictoires, et, par là, moins convaincants. Tout en dénonçant vivement le recours à l'essence féminine par les hommes, Saint-Martin utilise elle-même une bonne part d'essentialisme lorsqu'elle pose comme élémentaire la différence sexuelle - biologique ou sociale - entre hommes et femmes et surtout l'impact de celle-ci sur l'écriture. Ainsi, sur la question d'une stylistique au féminin, elle semble hésiter à trancher radicalement, c'est-à-dire à prétendre que toute auteure appartiendrait nécessairement, de par son genre (gender), à l'écriture féminine. Plutôt, elle note : "on est en droit de parler d'une multiplicité de stylistiques au féminin, qui varient selon les auteures tout en demeurant liées de près à la mère et au maternel » ( $p$. 45). Cette nuance, si elle a le mérite de complexifier la question, ne convainc pas. On aurait aimé que l'auteure d'un essai aussi fortement ancré 
dans la théorie s'attaque de front au problème épineux de "l'identité de l'auteur ". Cela aurait été d'autant plus intéressant que cette question se trouve au centre d'une part importante de la critique littéraire actuelle, des gay studies aux black studies en passant par les aboriginal studies, sans parler, évidemment, des women studies. La controverse n'est donc pas près de s'éteindre...

Élisabeth Rousseau

Collège André-Grasset

\section{Annie Becquer, et al.}

Femme, j'écris ton nom... Guide d'aide à la féminisation des noms de métiers, titres, grades et fonctions

Paris, La Documentation française, 1999, 124 p.

"Le français dispose de ressources morphosyntaxiques qui permettent une féminisation conforme au génie de la langue dans quasiment tous les cas. "Cette phrase qui figure en quatrième de couverture de Femme, j'écris ton nom traduit bien la position que le Québec a prise et prônée depuis une vingtaine d'années quant à la féminisation des appellations de personnes. On sait qu'effectivement nous avons fait œuvre de pionniers et de pionnières en la matière. La Suisse a emboîté le pas quelques années plus tard, puis la Belgique au début des années ' 90 . Mais la France restait à la traîne, malgré une première circulaire administrative publiée en 1986, énonçant des règles de formation des féminins et encourageant leur emploi... C'est pourquoi ce guide rédigé par l'Institut national de la langue française (Inalf) de France vient à point. Préfacé par Lionel Jospin, le premier ministre en personne, il répond à une demande que ce promoteur de la parité et de l'égalité avait lui-même formulée.

Voilà un petit ouvrage de vulgarisation, accessible à tous ceux et celles que la langue intéresse, qui résume de façon fort intéressante l'historique de la question, présente les règles de féminisation, aborde les objections et les difficultés rencontrées, et expose le mode de constitution de la liste des substantifs féminins proposés. Cette liste 